\title{
DMF Decomposition and Nitrogen Removal Performance by a Mesh-Filtration Bioreactor under Acidic Conditions
}

\author{
Yuki KAMIMOTO ${ }^{1}$, Yoshiaki $\mathrm{KISO}^{1}$, Tatsuo $\mathrm{OGUCHI}^{1}$, Toshiro YAMADA $^{2}$, Jung-Yong $\mathrm{JUN}^{3}$, \\ Hongying $\mathrm{HU}^{4}$ \\ 1 Department of Ecological Engineering, Toyohashi University of Technology \\ Tempaku-cho, Toyohashi, 441-8580 Japan \\ 2 Department of Water Supply Engineering, National Institute of Public Health \\ 2-3-6 Minami, Wako-shi, Saitama 351-0197 \\ 3 Department of Environmental Engineering, College of Applied Science, Catholic University of Pusan, \\ Pugok 3-don, Keumjeong-gu, Pusan 609-751, Korea \\ 4 Department of Environmental Science and Engineering, Tsinghua University \\ Beijing, 100084, P.R. China
}

\begin{abstract}
$N, N$-Dimethylformamide (DMF) is a water-miscible polar solvent that is used in a wide variety of chemical industries. In Japan, $0.668 \times 10^{6} \mathrm{~kg}^{\cdot} \mathrm{y}^{-1}$ of DMF is discharged to the sewerage system and is ranked highest in the PRTR (2006). In this work, a bench-scale mesh-filtration bioreactor was employed for aerobic biological treatment of DMF. Synthetic wastewater containing 1000 $\mathrm{mg} \cdot \mathrm{L}^{-1}$ of DMF was fed into the reactor at 5 or 2.5 days of hydraulic retention time (HRT) and at a volumetric loading rate of 0.125 or $0.25 \mathrm{~kg}-\mathrm{DMF} \mathrm{m} \mathrm{m}^{-3} \mathrm{~d}^{-1}$; the $\mathrm{pH}$ of the reaction mixture was not controlled. Performances in removal of dissolved organic carbon (DOC) and nitrogen were examined. Although the $\mathrm{pH}$ of the reaction mixture decreased to around 3, DOC removal remained at more than $98 \%$, nitrification was complete, and about $45 \%$ of total nitrogen was removed. The rates of DMF decomposition, nitrification, and denitrification were evaluated by batch experiments, with the result that for these three biological reactions the sludge in the reactor showed significant activities even at $\mathrm{pH}$ 3. These results suggest that the sludge contained acidophilic nitrifying bacteria.
\end{abstract}

\section{Keywords:}

Wastewater treatment, DMF, mesh-filtration bioreactor, nitrification, denitrification, acidic condition

\section{Introduction}

$N, N$-Dimethylformamide (DMF: $\left.\left(\mathrm{CH}_{3}\right)_{2} \mathrm{NCHO}\right)$ is a water-miscible polar solvent used in a wide variety of chemical industries, such as the synthetic polymer, organic chemical, pharmaceutical, and agrochemical industries. DMF is emitted to the environment directly or via some treatment processes at a rate of $14.136 \times$ $10^{6} \mathrm{~kg}^{-1} \mathrm{y}^{-1}$ in Japan (2006), ranking ninth in the Pollutant Release and Transfer Register (PRTR) [1]. 4.782 $\times$ $10^{6} \mathrm{~kg}^{-} \mathrm{y}^{-1}$ is discharged to the atmosphere, $0.292 \times 10^{6} \mathrm{~kg}^{-1} \mathrm{y}^{-1}$ to surface water, $8.687 \times 10^{6} \mathrm{~kg}^{\cdot} \mathrm{y}^{-1}$ to wastewater treatment processes and $0.668 \times 10^{6} \mathrm{~kg}^{\cdot} \mathrm{y}^{-1}$ to sewerage systems. The last discharged amount is ranked highest in the PRTR.

Waste DMF is treated primarily by using physicochemical processes such as distillation, absorption, and adsorption. Because DMF is water miscible, however, it is difficult to remove it effectively by these physicochemical processes, and considerable amounts of waste DMF are discharged in wastewater. Although the biodegradability of DMF is relatively low, effective biological treatments by activated sludge and biofilm processes have been reported [2-8], in many cases by feeding diluted DMF to the reactors. Bromley-Challenor et al. [7] examined the decomposition properties of DMF under aerobic, fermentative, and nitrate-reducing conditions and reported that it is not decomposed effectively under anaerobic conditions. Ghosalb et al. [4] indicated two pathways for aerobic decomposition of DMF: 
decarbonylation followed by demethylation, and (2) two demethylation steps followed by decarbonylation. In the former pathway, dimethylamine and methylamine, which are produced as intermediate compounds, are toxic to biomass; this may account for the difficulties in treating wastewater with a high concentration of DMF.

The $\mathrm{C} / \mathrm{N}$ weight ratio of DMF is 2.57 , so it is important for biological DMF treatment processes to be able to remove nitrogen as well as organic carbon effectively. Funaishi et al. [8] reported that nitrogen could not be removed by an activated sludge system but was removed effectively by an anoxic-oxic process.

Membrane bioreactors may be promising for the treatment of low degradable or refractory organic compounds, because this type of reactor can maintain a high concentration of bacteria even when their growth rate is low. In our previous work [9-13], we found that a mesh-filtration bioreactor (a reactor equipped with a mesh- filtration unit instead of a membrane) was able to maintain biomass at a very high concentration. In this process, stable filtration performance was obtained by intermittent filtration under low $\mathrm{pH}$ conditions [11-13]. Building on these results, in this study we employed a mesh-filtration bioreactor for DMF treatment and examined its dissolved organic carbon (DOC) and nitrogen removal performances. The $\mathrm{pH}$ of the reaction mixture was not controlled, because acidic conditions are preferable in the mesh filtration process [11-13]. DMF decomposition, nitrification, and denitrification rates were also examined by batch-type experiments using biomass obtained from the reactor.

\section{Experimental}

\subsection{Reactor setup}

The reactor consisted of a polyacrylate cylinder (working volume, $8 \mathrm{~L}$ ) equipped with a mesh-filtration module (nylon mesh: opening size, $100 \mu \mathrm{m}$; module size, $75 \mathrm{~cm} \times 90 \mathrm{~cm}$; effective mesh area, $135 \mathrm{~cm}^{2}$ ) at the bottom of the reactor (Fig. 1). The reactor was set up in the laboratory, and water temperature (which was around $20^{\circ} \mathrm{C}$ ) was not controlled. A diffuser was installed under the mesh module for air supply and for cleaning of the mesh surface. The reactor was aerated, except during the filtration period. Filtration was carried out by introducing a hydraulic pressure difference between the water level in the reactor and the effluent port. Because the initial filtrate from the mesh module contained suspended solids (SS) at a high concentration, the initial $1 \mathrm{~min}$ of filtrate was returned to the reactor. Thereafter, the filtrate was collected as effluent. After the filtration finished, aeration was restarted.



Fig. 1 Schematic figure of the mesh filtration bioreactor

\subsection{Treatment of synthetic DMF Wastewater}

Activated sludge was obtained from the domestic wastewater treatment facility at our institution (extended aeration process) and inoculated into the reactor after pre-cultivation with the synthetic DMF wastewater by fill and draw for more than 2 weeks. The synthetic wastewater (Table 1) was fed into the reactor by peristaltic pumping at a loading rate of 1.6 or $3.2 \mathrm{Ld}^{-1}$ for $20 \mathrm{~h}$ each day with a hydraulic retention time (HRT) of 5 or 2.5 days, respectively. Filtration was conducted twice or four times per day, and $0.8 \mathrm{~L}$ of the effluent was withdrawn during each mesh filtration operation. The time required to filter $0.8 \mathrm{~L}$ of wastewater was measured as the filtration time. Dissolved oxygen (DO) in the reactor was kept at $2-3 \mathrm{mg} \cdot \mathrm{L}^{-1}$ under aerated conditions. The experiments were conducted over 1 year. The experimental conditions are summarized in Table 2. 


\subsection{Rates of DMF decomposition, nitrification, and denitrification}

The DMF decomposition rate of the biomass obtained from the reactor was measured. The biomass was collected by centrifugation ( $4650 \mathrm{~g}, 3 \mathrm{~min})$ and washed twice with pure water. The batch-type experiments were conducted at $\mathrm{pH} 3,5$, and 7: the $\mathrm{pH} 7$ solution was prepared with $0.01 \mathrm{M}$ phosphate buffer; the $\mathrm{pH} 5$ solution was prepared with $0.01 \mathrm{M}$ phosphate buffer and $\mathrm{H}_{2} \mathrm{SO}_{4}$; and the $\mathrm{pH} 3$ solution was adjusted with $\mathrm{H}_{2} \mathrm{SO}_{4}$ and $\mathrm{NaOH}$. The initial DMF concentration was adjusted to $50 \mathrm{mg}-\mathrm{C} \cdot \mathrm{L}^{-1}$.

Nitrification and denitrification rates of the biomass obtained from the reactor were also measured. Biomass obtained from the domestic wastewater treatment facility at our institution was used in a control experiment. The $\mathrm{pH}$ was adjusted to 3,5, and 7. For measurement of the nitrification rate, $\mathrm{NH}_{4} \mathrm{Cl}$ was used as the substrate. For measurement of the denitrification rate, $\mathrm{NaNO}_{3}$ and methanol were used as substrates, and the weight ratio of initial methanol to $\mathrm{NO}_{3}-\mathrm{N}$ was more than 5 .

Table 1 Composition of the synthetic wastewater

\begin{tabular}{cc}
\hline Substance & Concentration $\left(\mathrm{mg} \cdot \mathrm{L}^{-1}\right)$ \\
\hline $\mathrm{DMF}$ & 1000 \\
$\mathrm{Na}_{2} \mathrm{HPO}_{4}$ & 176 \\
$\mathrm{KCl}$ & 5 \\
$\mathrm{CaCl}_{2}$ & 1.8 \\
$\mathrm{MgSO}_{4}$ & 7 \\
Alkalinity & 100 \\
\hline
\end{tabular}

Table 2 Operation conditions

\begin{tabular}{|c|c|c|}
\hline Phase & 1 & 2 \\
\hline Period (d) & $0-157$ & $158-419$ \\
\hline $\operatorname{HRT}(d)$ & 5 & 2.5 \\
\hline Filtration $\left(\right.$ times $\left.\cdot \mathrm{d}^{-1}\right)$ & 2 & 4 \\
\hline \multicolumn{3}{|l|}{ Synthetic wastewater } \\
\hline $\mathrm{DMF}\left(\mathrm{mg} \cdot \mathrm{L}^{-1}\right)$ & & 1000 \\
\hline $\mathrm{COD}_{\mathrm{Cr}}\left(\mathrm{mg} \cdot \mathrm{L}^{-1}\right)$ & & 986 \\
\hline TOC $\left(\mathrm{mg} \cdot \mathrm{L}^{-1}\right)$ & & 493 \\
\hline $\mathrm{T}-\mathrm{N}\left(\mathrm{mg} \cdot \mathrm{L}^{-1}\right)$ & & 192 \\
\hline $\mathrm{pH}(-)$ & & 8.14 \\
\hline \multicolumn{3}{|l|}{ Volumetric Loading Rate } \\
\hline $\mathrm{COD}_{\mathrm{Cr}}\left(\mathrm{kg} \cdot \mathrm{m}^{-3} \cdot \mathrm{d}^{-1}\right)$ & 0.125 & 0.250 \\
\hline $\operatorname{TOC}\left(\mathrm{kg} \cdot \mathrm{m}^{-3} \cdot \mathrm{d}^{-1}\right)$ & 0.062 & 0.125 \\
\hline $\mathrm{T}-\mathrm{N}\left(\mathrm{kg} \cdot \mathrm{m}^{-3} \cdot \mathrm{d}^{-1}\right)$ & 0.024 & 0.048 \\
\hline
\end{tabular}

\subsection{Analytical methods}

All effluent samples were filtered with a cellulose acetate membrane filter $(0.45 \mu \mathrm{m})$. DOC was determined by using a TOC analyzer (TOC-5000, Shimadzu, Kyoto, Japan). Ammonia and nitrite were analyzed by phenate method [15] and by colarimetric method [16], respectively. Nitrate was analyzed by an ion chromatograph equipped with a column of Tosoh TSKgel IC-Anion PW $\mathrm{XL}_{\mathrm{XL}}$ Kjeldahl nitrogen was analyzed [16], and organic nitrogen was evaluated from the difference between Kjeldahl nitrogen and ammoniac nitrogen.

\subsection{Respiration activity of the biomass}

The metabolically active cells in the sludge were evaluated on the basis of the respiration activity detected by the 5-cyano-2,3-ditolyl tetrazolium chloride (CTC) staining method. The biomass was obtained from the reactor on the 407th day. CTC is converted to fluorescent CTC-formazan precipitates when reduced by biological redox reactions such as respiratory electron transport. We used the CTC staining method as modified by Yoshida and Hiraishi [14]. The sludge samples were sonicated in an ice bath for 90 
s with a 2-s intermittent burst $(20 \mathrm{kHz}$; output power, $50 \mathrm{~W})$ and immediately used for the CTC staining process. The activated sludge was harvested by centrifugation $(8230 \mathrm{~g}, 5 \mathrm{~min})$, washed three times with 50 $\mathrm{mM}$ 3-morpholinepropanesulfonic acid (MOPS) buffer (pH 6.5), and resuspended in $50 \mathrm{mM}$ MOPS buffer. The reaction mixture containing $870 \mu \mathrm{L}$ of sludge, $120 \mu \mathrm{L}$ of $50 \mathrm{mM} \mathrm{CTC}$, and $10 \mu \mathrm{L}$ of the substrate mixture $(0.05 \%$ for peptone and yeast extract and $1 \mathrm{mM}$ for glucose and succinate) was incubated in a water bath at $30{ }^{\circ} \mathrm{C}$ for $4 \mathrm{~h}$ with gentle shaking. Five microliters of the cell suspension was spotted on a slide glass and fixed by drying at $30^{\circ} \mathrm{C}$ for $5 \mathrm{~min}$. The fixed cells were counterstained for $5 \mathrm{~min}$ with $10 \mu \mathrm{L}$ of SYBR green I solution: the dye solution used was a $10^{-4}$-fold dilution of the purchased solution (Molecular Probes, Eugene, OR, USA). Then, the slide glass was rinsed with cooled MilliQ water to remove the excess dye and dried at room temperature in the dark. A drop of Citiflour (Citiflour, Ltd., London, UK) was placed on top of each sample. The samples were observed under an Olympus BX-50 epifluorescence microscope equipped with a Flovel FD-120M digital CCD camera (Flovel Co., Tokyo, Japan). The number of positive cells per a view area was counted, and 11 view areas were measured.

\section{Results and discussion}

\subsection{Filtration performance}

The concentration of mixed liquor suspended solids (MLSS) was initially about $4000 \mathrm{mg} \cdot \mathrm{L}^{-1}$, and it was increased to $5000 \mathrm{mg} \cdot \mathrm{L}^{-1}$ at HRT $=5 \mathrm{~d}$ (Phase 1). The HRT was then changed to $2.5 \mathrm{~d}$ (Phase 2), and the MLSS was increased to $11000 \mathrm{mg} \cdot \mathrm{L}^{-1}$. The mesh-filtration bioreactor was able to maintain a high concentration of biomass. Profiles of MLSS, mixed liquor volatile suspended solids (MLVSS), filtration time, effluent SS, and pH are shown in Fig. 2.

When the loading rate was low (Phase 1), filtration occurred very quickly (filtration time: about 10 $\mathrm{min}$ ), and the effluent SS also remained very low (about $6 \mathrm{mg} \cdot \mathrm{L}^{-1}$ ). These results indicate that the cake layer that formed on the mesh surface could effectively block sludge particles.

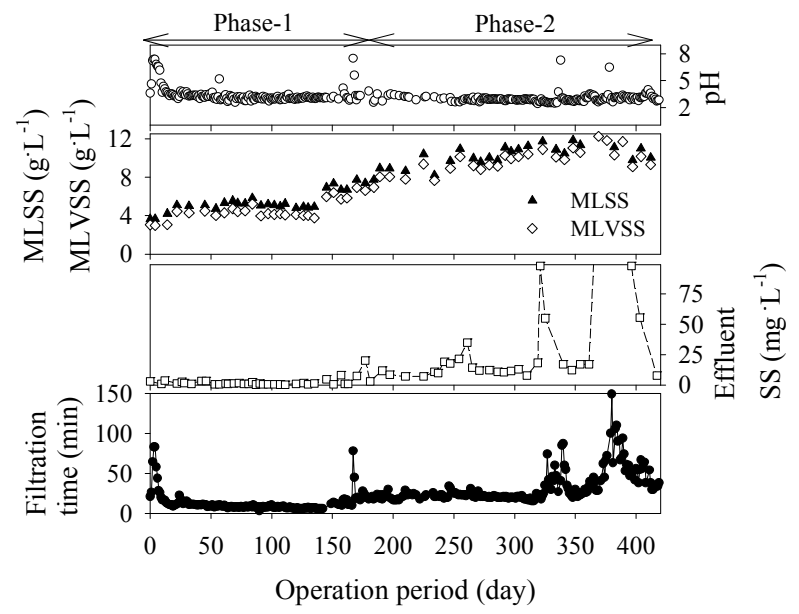

Fig. 2 Profiles of MLSS, MLVSS, filtration time, effluent SS and pH

When the loading rate increased during Phase 2, the filtration time increased to more than $20 \mathrm{~min}$. At around the 170th day, the filtration time spiked, and the effluent $\mathrm{SS}$ and $\mathrm{pH}$ also increased abruptly. At this time the aeration had stopped because the blower malfunctioned. The blower was replaced, and aeration was restarted. Since the $\mathrm{pH}$ in the reactor decreased again within 3 days, the feeding of synthetic wastewater was restarted. As a result, both the filtration time and the effluent SS recovered.

The filtration time was also long during days 330-340. At this time, the effluent $\mathrm{pH}$ decreased to 2.5 , and deflocculation of the sludge was observed. The deflocculation may have been induced by strongly acidic conditions, because the filtration performance recovered after the $\mathrm{pH}$ was increased to 3 by the addition of a small amount of $\mathrm{NaHCO}_{3}$ to the synthetic wastewater. The filtration time was also long during days 370-410. At this time defloculation was also observed, but the reasons were not clear. 


\subsection{DMF decomposition performance}

We examined the profile of dissolved organic carbon (DOC) in the effluent (Fig. 3). During the initial few days, high concentrations of DOC $\left(45-65 \mathrm{mg}-\mathrm{C} \cdot \mathrm{L}^{-1}\right)$ were observed, but DOC remained lower than 10 $\mathrm{mg} \cdot \mathrm{L}^{-1}$ during the experimental period (average DOC $=6 \mathrm{mg}-\mathrm{C} \cdot \mathrm{L}^{-1}$ ). The DOC concentration of the synthetic wastewater was $493 \mathrm{mg} \cdot \mathrm{L}^{-1}$, and the DOC removal rate was more than $98 \%$. These results indicate that the fed DMF had been almost completely mineralized and that reaction intermediates, such as $\mathrm{N}$-methylamide, formamide, dimethylamine, and methylamine, did not accumulate. The apparent overall DMF decomposition rate was evaluated as $4.06 \mathrm{mg}-\mathrm{C} \cdot \mathrm{L}^{-1} \cdot \mathrm{h}^{-1}$ in Phase 1 and $8.12 \mathrm{mg}-\mathrm{C} \cdot \mathrm{L}^{-1} \cdot \mathrm{h}^{-1}$ in Phase 2, where the effluent DOC was assumed to be caused by residual DMF.

The DMF decomposition rates were also examined by batch experiments, conducted at $\mathrm{pH} 3,5$, or 7 , with the sludge obtained from the reactor on the 419th day. In these experiments, the DMF decomposition rate was evaluated by the rate of decrease of DOC. The DMF decomposition rate was approximated as a first-order reaction (Fig. 4). The relationship between the reaction rate constant $\left(\mathrm{mg}-\mathrm{C} \cdot \mathrm{L}^{-1} \cdot\left(\mathrm{g}^{-1}-\mathrm{VSS} \cdot \mathrm{L}^{-1}\right) \cdot \mathrm{h}^{-1}\right)$ and $\mathrm{pH}$ is illustrated in Fig. 5. The highest decomposition rate was obtained at $\mathrm{pH} 3$, and the rate decreased as the $\mathrm{pH}$ was increased.



Fig. 3 Profile of the effluent DOC



Fig. 4 DMF decomposition rates



Fig.5 Effect of pH on the rate constant of DMF decomposition

The DMF decomposition rate was simulated by using the reaction rate constant $\mathrm{pH} 3$ shown in Fig. $\mathbf{5}$. The calculation was conducted under the following conditions: the reaction rate constant $=0.123$ (g-VSS $\left.\mathrm{L}^{-1}\right)^{-1} \cdot \mathrm{h}^{-1}$, MLVSS $=11 \mathrm{~g} \cdot \mathrm{L}^{-1}$ and DOC $=5 \mathrm{mg}-\mathrm{C} \cdot \mathrm{L}^{-1}$. The simulated value of $6.78 \mathrm{mg}-\mathrm{C} \cdot \mathrm{L}^{-1} \cdot \mathrm{h}^{-1}$ was similar to the apparent overall DMF decomposition rate $\left(8.12 \mathrm{mg}-\mathrm{C}^{-} \mathrm{L}^{-1} \cdot \mathrm{h}^{-1}\right)$ in the reactor. However, it should be noted that the microbial metabolites of DMF may contribute to the effluent DOC from the reactor. When the DMF concentration in the effluent is lower than $5 \mathrm{mg}-\mathrm{C} \cdot \mathrm{L}^{-1}$, the simulated reaction rate may decrease 
significantly.

The respiration activity of the biomass in the reactor was monitored by double staining with CTC and SYBR green. The proportion of cells stained by both CTC and SYBR green relative to those stained by SYBR green alone was $33.0 \% \pm 6.0 \%$, indicating significant aerobic respiration activity, although the value was lower than that for common activated sludge $(44.2 \% \pm 2.3 \%)$ [14]. Some DMF-decomposing bacteria have been isolated $[5,6]$, but these bacteria were cultivated at near neutral $\mathrm{pH}$.

\subsection{Nitrification and denitrification properties}

Because the nitrogen content of DMF is high $(\mathrm{C} / \mathrm{N}=2.57)$, the synthetic wastewater (1000 $\mathrm{mg}-\mathrm{DMF} \cdot \mathrm{L}^{-1}$ ) contained $191.8 \mathrm{mg} \cdot \mathrm{L}^{-1}$ of nitrogen, so evaluation of total nitrogen (T-N) removal by biological DMF removal processes is also important. We examined the profiles of the nitrogen components (Fig. 6). Organic nitrogen (Org-N) was present in Phase 1 but disappeared during part of Phase 2. $\mathrm{NH}_{4}-\mathrm{N}$ was also observed in Phase 1 but then disappeared until the latter half of Phase $2 . \mathrm{NO}_{2}-\mathrm{N}$ was observed at only trace levels throughout the experimental period, and most nitrogen was $\mathrm{NO}_{3}-\mathrm{N}$ during Phase 2 . Considering that the $\mathrm{pH}$ in the reactor was kept at around 3, these results were surprising and unusual. Although T-N removal fluctuated, the average T-N removal during Phase 2 was $45 \%$. These results suggest that denitrification also occurred despite the acidic conditions. The T-N removal amount may correspond to the denitrification ratio, and the limited denitrification may have been caused by an insufficiency in the amount of hydrogen donor owing to the low $\mathrm{C} / \mathrm{N}$ ratio of the $\mathrm{DMF}$ and the acidic condition of the reaction mixture.

The effects of $\mathrm{pH}$ on nitrification and denitrification rates were examined in batch-type tests. For the tests, sludge obtained from the reactor (S-1) and activated sludge obtained from the domestic wastewater treatment facility at our institution (S-2) were used. The nitrification and denitrification rates were measured at $\mathrm{pH} \mathrm{3,} \mathrm{5,} \mathrm{and} 7$ (Figs. 7 and 8). In the case of the S-2 sludge, both nitrification and denitrification activities were highest at $\mathrm{pH} 7$ and were not observed at $\mathrm{pH} 3$; these are the results that have been observed commonly. On the other hand, in the case of the S-1 sludge, nitrification activity was observed even at $\mathrm{pH} 3$ and was higher at $\mathrm{pH} 5$ than that in the $\mathrm{S}-2$ sludge, although the nitrification activity was lower than that in the S-2 sludge at $\mathrm{pH}$ 7. The highest denitrification activity in the S-1 sludge was observed at $\mathrm{pH} 3$, although a large fluctuation was observed. Considering that the denitrification rate in the $\mathrm{S}-1$ sludge at $\mathrm{pH} 3$ was higher than the nitrification rate at $\mathrm{pH} 7$, the low rate of T-N removal in the reactor (Fig. 6) may have been caused by insufficiency in the amount of hydrogen donor.



Fig. 6 Profiles of nitrogen components



Fig. 7 Effect of $\mathrm{pH}$ on nitrification rate S-1: the sludge obtained from the reactor S-2: the sludge obtained from a domestic wastewater treatment facility 


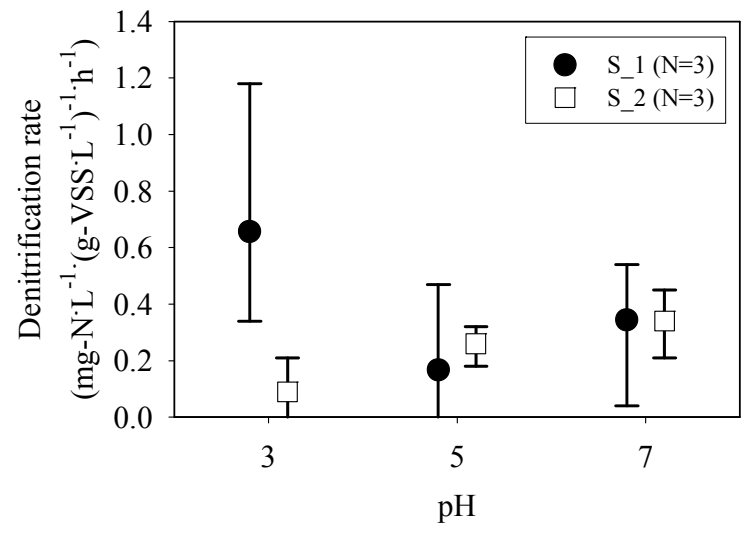

\section{Fig. 8 Effect of pH on denitrification rate S-1: the sludge obtained from the reactor S-2: the sludge obtained from a domestic wastewater treatment facility}

These results suggest that the nitrifying and denitrifying bacteria in the reactor were acidophilic. Although bacteria having activity under acidic conditions are rare, Tarre et al. [15] isolated acidophilic nitrifying bacteria from a soil and observed their nitrifying activity at $\mathrm{pH}$ 3.2. However, acidophilic nitrifying and denitrifying bacteria have not been isolated from activated sludges in wastewater treatment processes. The $\mathrm{pH}$ of the reaction mixture in our reactor decreased to a very low value $(\mathrm{pH} 3)$ owing to the low alkalinity of the synthetic wastewater. The mesh-filtration device effectively prevented wash-out of biomass from the reactor, which retained a high concentration of biomass. Because of the long-term operation of the reactor, the unique bacterial consortium described above may have become acclimated. It will be important in future work to reveal the characteristics of the biomass in the reactor.

\section{Conclusion}

DMF treatment was conducted in a mesh- filtration bioreactor without $\mathrm{pH}$ control. Although the $\mathrm{pH}$ of the reaction mixture decreased to a very low level $(\mathrm{pH} 3)$, the DMF was effectively mineralized, and complete nitrification and partial denitrification $(45 \%)$ were also observed. The sludge in the reactor showed higher activities of DMF decomposition, nitrification and denitrification at $\mathrm{pH} 3$ than activated sludge, suggesting that acidophilic heterotrophic and nitrifying bacteria had become acclimated in the reactor. Characterization of the unique bacteria in the reactor remains a subject for future investigation.

\section{Acknowledgements}

This work was financially supported by the Strategic International Cooperative Program- Development of advanced treatments and recycle systems of wastewater for sustainability and environmental risk reduction, sponsored by the Japan Science and Technology Agency. We wish to thank Dr. A. Hiraishi, Professor at Toyohashi University of Technology, for helpful advice and technical support during the measurement of respiration activity of the sludge in the reactor by the CTC staining method.

\section{References}

[1] http://www.prtr-info.jp/prtrinfo/

[2] Yamauchi, K., Nakao, K., Fujii, K. (1981) Treatment of wastewater from organic chemical industries by trickling filter (IV) - Treatment performance of DMF, J. Water Waste, (Japanese), 23, 838-842.

[3] Carter, J.L., Young, D.A. (1984). Biodegradation of chemical plant wastewater containing dimethylformamide, Proc. Ind. Waste Conf., 38, 481-486.

[4] Ghosalb, O., Cevey, P., Küenzi, M., Schär, H.P. (1985). Biodegradation of chemical waste by specialized methylotrophs, an alternative to physical methods of waste disposal, Conservation \& Recycling, 8, 47-71.

[5] Hu, H., Nakagime, K., Fujie, K., Urano, K. (1992). Analysis of bacterial acclimation to 
dimethylformamide on the basis of quinone profile in aerobic biofilter, J. Jpn. Soc. Water Environ. (Japanese), 15(10), 726-733.

[6] Okazaki, M., Hamada, T., Fujii, H., Kusudo, O., Mizobe, A., Matsuzawa, S. (1995). Development of poly(vinyl alcohol) hydrogel for waste water cleaning. II. Treatment of $N, N$-dimethylformamide in waste water with poly(vinyl alcohol) gel with immobilized microorganisms, J. Appl. Polym. Sci., 58, 2243-2249.

[7] Bromely-Challenor, K.C.A., Caggiano, N., Knapp, J. S. (2000). Bacterial growth on $\mathrm{N}, \mathrm{N}$-dimethylformamide: implications for the biotreatment of industrial wastewater, J. Ind. Microbiol. Biotechnol., 25, 8-16.

[8] Funaishi, K., Miyamae, H., Li, Y.-Y., (2003). Activated sludge treatment and nitrogen removal of wastewater containing $N, N$-dimethylformamide, $J$. Water Waste, (Japanese), 45, 414-420.

[9] Kiso, Y., Jung, Y., Ichinari, T., Kitao, T., Nishimura, K., Min, K. (2000). Wastewater treatment performance of a filtration bio-reactor equipped with a mesh as a filter material, Water Research, 34, $4143-4150$

[10] Kiso, Y., Jung, Y.-J., Park, M.-S., Wang, W.H., Shimase, M., Yamada, T., Min, K.-S. (2005). Coupling of sequencing batch reactor and mesh filtration: operational parameters and wastewater treatment performance, Water Research, 39, 4887-4898.

[11] Wang, W.H., Jung, Y.-J. Kamimoto, Y., Kiso, Y. (2005). Excess sludge reduction by a pilot scale SBR equipped with a mesh filtration unit, INCHEM TOKYO 2005, pp. 71-75, Tokyo, Japan, Nov. 17-18.

[12] Wang, W.H., Jung, Y.-J., Kiso, Y., Yamada, T., Min, K.-S. (2006). Excess sludge reduction performance of SBR process equipped with a submerged mesh filter unit, Process Biochemistry, 41, 745-751.

[13] Wang, W.H., Yamada, T., Kiso, Y. (2006). Effects of pH on excess sludge reduction performance of mesh filtration bioreactor, J. Domestic Wastewater Treatment Res., (Japanese) 18, 1-10

[14] Yoshida, N. and Hiraishi, A. (2004). An improved redox dye-staining method using 5-cyano-2,3-ditoryl tetrazolium chloride for detection of metabolically active bacteria in activated sludge, Microbial Environ., 19, 61- 70.

[15] American Public Health Association, American Water Works Association and Water Environmental Federation, (2005). Standard method for examination of water and wastewater, 21st ed.

[16] Japanese Standards Association (1998). Japanese Industrial Standards, JIS K0102

[17] Tarre, S., Beliavski, M., Denekamp, N., Green, M., Gieseke, A., de Beer, D. (2004). High nitrification rate at low $\mathrm{pH}$ in a fluidized bed reactor with chalk as the biofilm carrier, Water Sci. Technol., 49, 99-105 